\title{
Toxicity of imidacloprid and chlorpyrifos against German cockroaches Blattella germanica
}

\author{
Mozhgan Baniardalani ${ }^{1}$, Asma Arfa Rahimian ${ }^{1}$, Abedin Saghafipour ${ }^{2}$, Hamid Reza Basseri ${ }^{1}$, Majid Kababian ${ }^{1,3}$ and \\ Jalil Nejati ${ }^{4}$
}

1. Department of Medical Entomology and Vector Control, School of Public Health, Tehran University of Medical Sciences, Tehran, Iran; 2. Department of Public Health, Faculty of Health, Qom University of Medical Sciences, Qom, Iran; 3. Students' Scientific Research Center, Tehran University of Medical Sciences, Tehran, Iran; 4. Health Promotion Research Center, Zahedan University of Medical Sciences, Zahedan, Iran.

Corresponding author: Majid Kababian, e-mail: majid kbi69@yahoo.com

Co-authors: MB: baniardalan@sina.tums.ac.ir, AAR: asmaarfa91@gmail.com, AS: abed.saghafi@yahoo.com, HRB: basserih@tums.ac.ir, JN: jalilnejati@yahoo.com

Received: 02-10-2019, Accepted: 04-12-2019, Published online: 30-12-2019

doi: www.doi.org/10.14202/IJOH.2019.107-112 How to cite this article: Baniardalani M, Rahimian AA, Saghafipour A, Basseri HR, Kababian M, Nejati J. Toxicity of imidacloprid and chlorpyrifos against German cockroaches Blattella germanica. Int J One Health 2019;5:107-112.

\begin{abstract}
Background and Aim: As a mechanical vector of some communicable diseases and a self-adaptive species to human environments, the German cockroach can transmit pathogens, such as bacteria, viruses, and fungi, to human beings. This study was conducted to determine the toxicity of imidacloprid and chlorpyrifos against German cockroaches.
\end{abstract}

\begin{abstract}
Materials and Methods: In this experimental study, the last instar German cockroach nymphs were used to test their sensitivity to imidacloprid and chlorpyrifos insecticides by the contact and bait methods. In bioassay (jar test), the nymphs were isolated from the main colony and were exposed to the insecticides for $30 \mathrm{~min}$. The mortality rate was recorded $24 \mathrm{~h}$ after the recovery time. In bioassay (bait), 24-96 $\mathrm{h}$ after exposure to the poisonous bait, the mortality rate was recorded and regression analysis was run to analyze the data in the SPSS software (IBM, Chicago, USA).
\end{abstract}

Results: The lethal doses (LD) of imidacloprid and chlorpyrifos were $9.5 \mathrm{mg} / \mathrm{m}^{2}$ and $39.78 \mathrm{mg} / \mathrm{m}^{2}$, respectively. The $\mathrm{LD}_{50}$ for imidacloprid and chlorpyrifos were 2.66 and $9.92 \mathrm{mg} / \mathrm{m}^{2}$, respectively. Results revealed that the highest concentration of imidacloprid (45\%) could cause the highest mortality rate (95\%) $24 \mathrm{~h}$ after exposure. There is a significant difference in the mortality of the samples during the follow-up period. Moreover, the chlorpyrifos smeared bait, with a concentration of $16 \%$ after $24 \mathrm{~h}$, had the highest mortality rate $(95 \%)$.

Conclusion: The highest mortality rate occurred in the ingestion of imidacloprid smeared bait within the first $48 \mathrm{~h}$ after being exposed to the insecticide. Therefore, the results show that imidacloprid can prove significantly effective in controlling cockroaches.

Keywords: Blattella germanica, chlorpyrifos, German cockroach, imidacloprid.

\section{Introduction}

Despite the harmful effects of using chemical pesticides on human health, chemical pesticides are still the most appropriate method for integrated pest management (IPM) and for controlling arthropod-borne disease vectors [1]. Blattella germanica L. is one of the most important species of pests all over the world. This allergen insect is found in residential areas, restaurants, hotels, hospitals, and food storages [2]. The German cockroach as a mechanical vector can easily transmit pathogens such as bacteria, viruses, fungi, protozoa, and parasites because it has a small body size, special nutritional habits, and specific behavior. Besides, it can readily adapt itself to the

Copyright: Baniardalani, et al. This article is an open access article distributed under the terms of the Creative Commons Attribution 4.0 International License (http://creativecommons.org/ licenses/ by/4.0/), which permits unrestricted use, distribution, and reproduction in any medium, provided you give appropriate credit to the original author(s) and the source, provide a link to the Creative Commons license, and indicate if changes were made. The Creative Commons Public Domain Dedication waiver (http:// creativecommons.org/ publicdomain/zero/1.0/) applies to the data made available in this article, unless otherwise stated. human environment and the causative agents of allergic diseases [3].

This pest is usually controlled using pesticides. Even in advanced IPM systems, the key to the German cockroach control is the use of chemicals and synthetic insecticides [4]. Research on insecticides and new methods to fight against German cockroaches has been continued due to the medical and economic importance of this pest in the urban environment [5]. Nevertheless, the frequent and extensive use of pesticides against German cockroaches has caused resistance to pesticides so that they are second-ranked, after the housefly (Musca domestica), in terms of resistance to many types of insecticides [6,7]. As of today, the resistance of this insect to various insecticides (such as organochlorine, carbamate, organophosphate, and pyrethroid groups) has been reported [8]. Some populations of this pest have been resistant to several different insecticides [9].

To prevent or delay insecticide resistance, it has been recommended to combat German cockroaches by the rotation method based on different insecticide groups [10]. The imidacloprid insecticide (SC 35\%), 
as a systemic insecticide with a contact-oral effect, belongs to neonicotinoid/chloronicotinyl groups used against pests and insects. The use of this product, even in limited dosage, is effective on a wide range of harmful insects. The way imidacloprid works are that it affects nicotinic acetylcholine receptors in the central nervous system of the insect [11]. In addition, chlorpyrifos is a phosphorus insecticide with dermal and oral effects that can control urban and agricultural pests [12].

In light of the above, this study was carried out to determine the susceptibility of insectary strain German cockroach (Dictyoptera: Blattellidae) to imidacloprid and chlorpyrifos insecticides.

\section{Materials and Methods}

\section{Ethical approval}

The study was approved by the Ethical Committee of Tehran University of Medical Sciences, Iran (IR.TUMS.VCR.REC.1397.083).

\section{Study area and data collection}

\section{Cockroach rearing}

In this experimental study, the last instar nymphs of the German cockroach, kept at the School of Public Health, Tehran University of Medical Sciences, were used to test the sensitivity of German cockroaches to imidacloprid and chlorpyrifos insecticides by the contact and bait methods. Environmental conditions including temperature $27 \pm 2$, relative humidity $60 \pm 10$, and a photoperiod of 12:12 (light-dark) h were observed for special containers to keep cockroaches (plastic containers of $4 \mathrm{~L}$ ). Dried bread and rodent food were the nutrition source of cockroaches. Bird dishes were used to provide water for cockroaches, and carbon dioxide gas was employed to anesthetize cockroach nymphs.

\section{Chemicals and pesticides}

Two technical grades of insecticides were used in this study: Chlorpyrifos 97\% (Ilia Samavaran Chemical Trading Company) and imidacloprid 97\% (Meshkfam Company, Fars, Iran).

\section{Bioassay test (jar method)}

The jar test was performed using the standard method as recommended by the WHO glass jar tests [13]. The surface of the containers was measured and stained with acetone-soluble insecticides. The cockroach nymphs were isolated from the main colony and were exposed to the insecticides for $30 \mathrm{~min}$. The mortality rate was recorded $24 \mathrm{~h}$ after the recovery time.

\section{Bioassay test (bait method)}

To prepare the insecticide bait, a combination of various ingredients including rice bran, wheat flour, rodent food, sugar, water, and insecticide solution (bait $10.5 \mathrm{~g}$ ) was used. The nymphs were kept hungry for 3 days and then the bait containing different concentrations of insecticide was given to the cockroaches for $3 \mathrm{~h}$. After the exposure time, the poisonous bait was replaced with poison-free baits.

\section{Statistical analysis}

The mortality rate of nymphs was recorded 24-96 $\mathrm{h}$ after exposure to the poisonous bait, and regression analysis was conducted to analyze the data in the SPSS software.

\section{Results}

In this study, the toxicity effect of two insecticides, namely, imidacloprid and chlorpyrifos, on German cockroach nymphs was tested using contact and bait methods. The results of the contact method experiment $(30 \mathrm{~min})$ on German cockroaches are shown in Tables- 1 and 2 and Figures- 1 and 2. Based on the results, it was observed that the lethal doses (LD) of imidacloprid and chlorpyrifos were $9.5 \mathrm{mg} / \mathrm{m}^{2}$ and $39.78 \mathrm{mg} / \mathrm{m}^{2}$, respectively. The $\mathrm{LD}_{50}$ for imidacloprid and chlorpyrifos were 2.66 and $9.92 \mathrm{mg} / \mathrm{m}^{2}$, respectively.

The results of the bait method experiment are shown in Tables-3 and 4. As shown, the highest concentration of imidacloprid (45\%) caused the highest mortality rate (95\%) $24 \mathrm{~h}$ after exposure. There was a significant difference in the mortality rate of the samples in the follow-up period. The chlorpyrifos smeared baits, with a concentration of $16 \%$ after $24 \mathrm{~h}$, had the highest mortality rate (95\%) (Figures-3 and 4).

\section{Discussion}

Reports on numerous cases of German cockroach resistance to many types of insecticides, including

Table-1: Susceptibility of imidacloprid to nymphs of German cockroach (insectary strain) by glass jar method.

\begin{tabular}{|c|c|c|c|c|c|c|c|}
\hline Dose $\left(\mathrm{mg} / \mathrm{m}^{2}\right)$ & $\mathbf{n}$ & Mortality (\%) & $\begin{array}{c}\text { LD }_{50} \pm \text { Lower band } \\
\text { - upper band }\end{array}$ & $\begin{array}{l}\text { LD }_{90} \pm \text { Lower band } \\
\text { - upper band }\end{array}$ & Slope \pm SE & $\chi^{2}(\mathbf{d f})$ & Y-intercept \\
\hline 9.5 & 40 & 100 & $2.66 \pm 1.14-4.03$ & $6.21 \pm 4.66-10.30$ & $0.00 \pm 0.00$ & $17.385(5)$ & -0.962 \\
\hline 7.5 & 40 & 90 & & & & & \\
\hline 5.5 & 40 & 85 & & & & & \\
\hline 3.5 & 40 & 72.5 & & & & & \\
\hline 1.5 & 40 & 52.5 & & & & & \\
\hline 1 & 40 & 17.5 & & & & & \\
\hline 0.5 & 40 & 10 & & & & & \\
\hline Control & 40 & 0 & - & - & - & - & - \\
\hline
\end{tabular}

$\mathrm{LD}_{50}=$ Lethal doses $50 \%$, $\mathrm{LD}_{90}=$ Lethal doses $90 \%$ 
Table-2: Susceptibility of chlorpyrifos to nymphs of German cockroach (insectary strain) by glass jar method.

\begin{tabular}{|c|c|c|c|c|c|c|c|}
\hline Dose $\left(\mathrm{mg} / \mathrm{m}^{2}\right)$ & $\mathbf{n}$ & Mortality (\%) & $\begin{array}{l}\text { LD }_{50} \pm \text { Lower band } \\
\text {-upper band }\end{array}$ & $\begin{array}{c}\text { LD }_{90} \pm \text { Lower band } \\
\text {-upper band }\end{array}$ & Slope \pm SE & $\chi^{2}(\mathrm{df})$ & Y-intercept \\
\hline 39.78 & 40 & 95 & $9.92 \pm 3.03-15.43$ & $27.73 \pm 20.67-47.83$ & $0.00 \pm 0.00$ & $17.385(5)$ & -0.714 \\
\hline 26.56 & 40 & 85 & & & & & \\
\hline 16.51 & 40 & 80 & & & & & \\
\hline 13.26 & 40 & 67.5 & & & & & \\
\hline 6.63 & 40 & 47.5 & & & & & \\
\hline 3.31 & 40 & 32.5 & & & & & \\
\hline 1.65 & 40 & 10 & & & & & \\
\hline Control & 40 & 0 & - & - & - & - & - \\
\hline
\end{tabular}

$\mathrm{LD}_{50}=$ Lethal doses $50 \%, \mathrm{LD}_{90}=$ Lethal doses $90 \%$

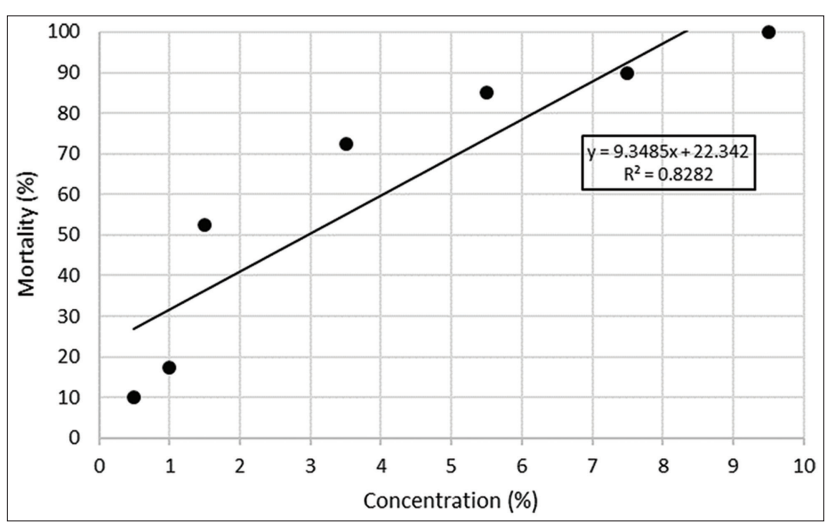

Figure-1: Regression line of imidacloprid against nymphs of German cockroach insectary strains by the WHO glass jar test method.

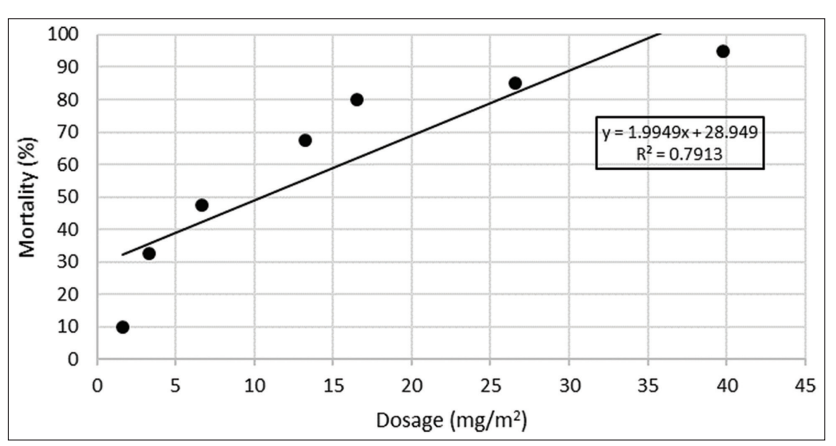

Figure-2: Regression line of chlorpyrifos against nymphs of German cockroach strains by the WHO glass jar method.

organophosphates, carbamates, and pyrethroids, have led researchers to identify and introduce new insecticides with various formulations [14]. In this study, the LD of two insecticides, imidacloprid and chlorpyrifos, were investigated for German cockroach nymphs. Imidacloprid is the first active ingredient in the chloronicotinyl class of insecticides, which has been used in various forms, such as poisonous baits and gels [15]. The minor similarity of chloronicotinyl to insect nicotinic acetylcholine receptor is considered as an important feature of this class, indicating its toxicity against insects. On the other hand, its $\mathrm{LD}_{50}$ is more than $5000 \mathrm{mg} / \mathrm{kg}$ of rat and mouse body weights [16]. Although some studies have shown that insecticide smeared baits can poison German cockroaches after $30 \mathrm{~min}$, the problem is that they can mostly recover from the poison. Indeed, the recovery chance for the cockroaches has a negative correlation with the insecticide concentration [17]. Similarly, the results of the current study showed that an increase in the concentration of insecticide significantly raised the percentage of killed cockroaches.

The previous studies have demonstrated that chlorpyrifos insecticide can cause rapid immobilization in German cockroaches for $72 \mathrm{~h}$ without any recovery. The $\mathrm{LD}_{50}$ of this insecticide showed moderate toxicity after $72 \mathrm{~h}$ [18]. Chlorpyrifos is one of the organophosphorus insecticides to which German cockroaches have built-up some resistance [19-21]. Therefore, some studies have proposed that synergistic compounds such as S, S, S-tributyl phosphorothioate, phenyl saligenin cyclic phosphonate, and $\mathrm{N}$, $\mathrm{N}$-dimethylcarbamate can increase the toxic effects of this insecticide to control German cockroaches. In the present study, although the results of experiments on this type of insecticide in the surface contact bioassay test were not satisfactory, more effective results were obtained in the form of poisonous baits, showing a higher mortality rate with a lower percentage than imidacloprid.

Two formulations for contact and bait methods were used in the current study to test insecticides. In spray formulation, the cockroaches' exposure to the active ingredient of the insecticide has particular importance, meaning that the insecticide must be effective in killing insects during a short period of exposure to surfaces covered with pesticide. In contrast, if using poisonous baits, the central factor is the ingestion of enough bait by the insect. In this case, the attractiveness of the bait and the possibility of its survival for a long time in the environment are of crucial importance [15]. Based on the behavior of cockroaches searching for baits, it seems that if these formulations are used, especially in certain environments such as hospitals, more effective results to control and fight cockroaches may be achieved. For example, a study in India showed that the use of imidacloprid gel on the field strain could reduce the German cockroach population in the $1^{\text {st }}$ week up to $82.8 \%$ and in the $8^{\text {th }}$ week up to $98.8 \%$ [15]. In another study conducted in Iran using imidacloprid gel (15.2\%) on the insectarium strain, the complete elimination of the German cockroach population was observed after 60 days [4]. 


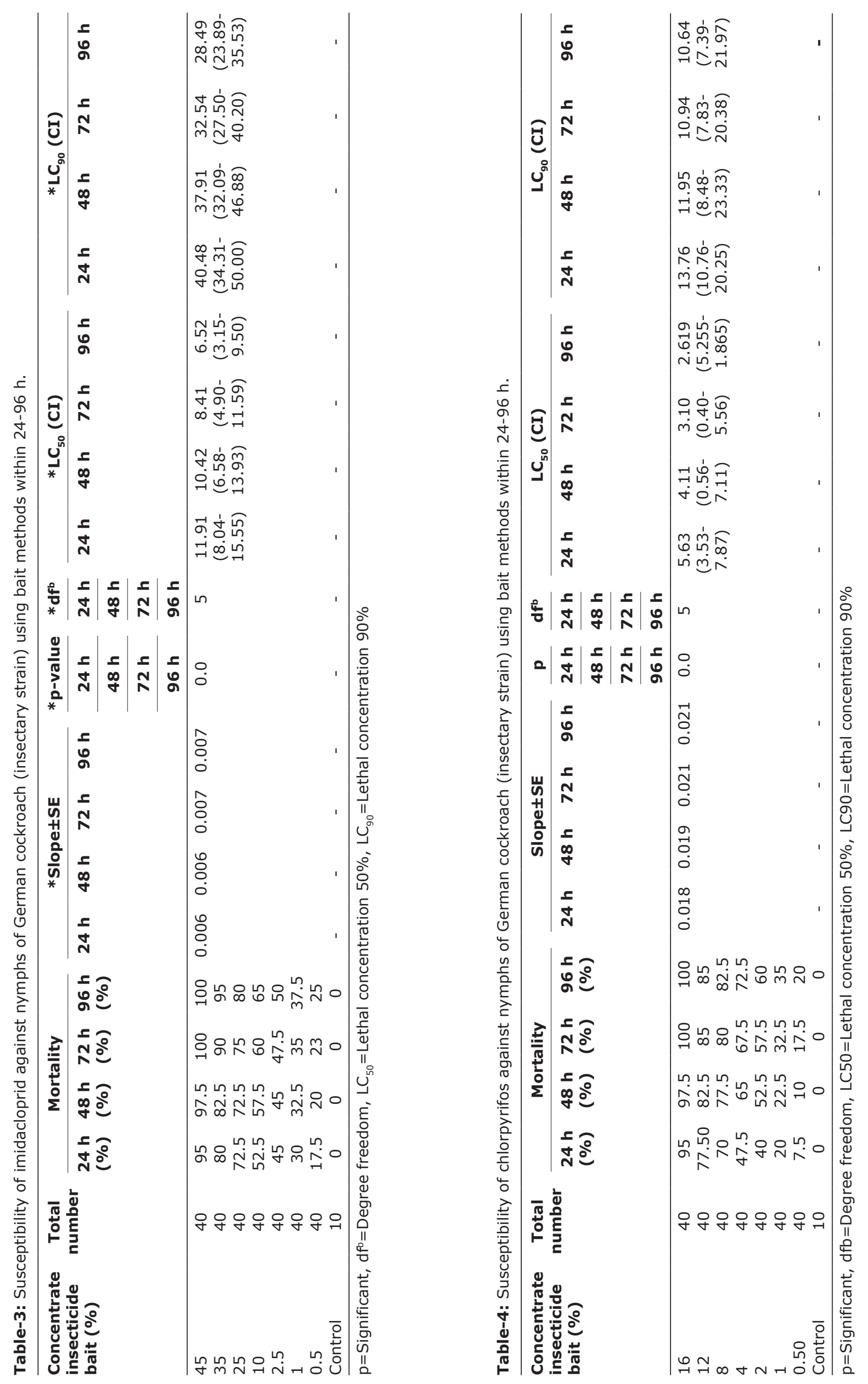




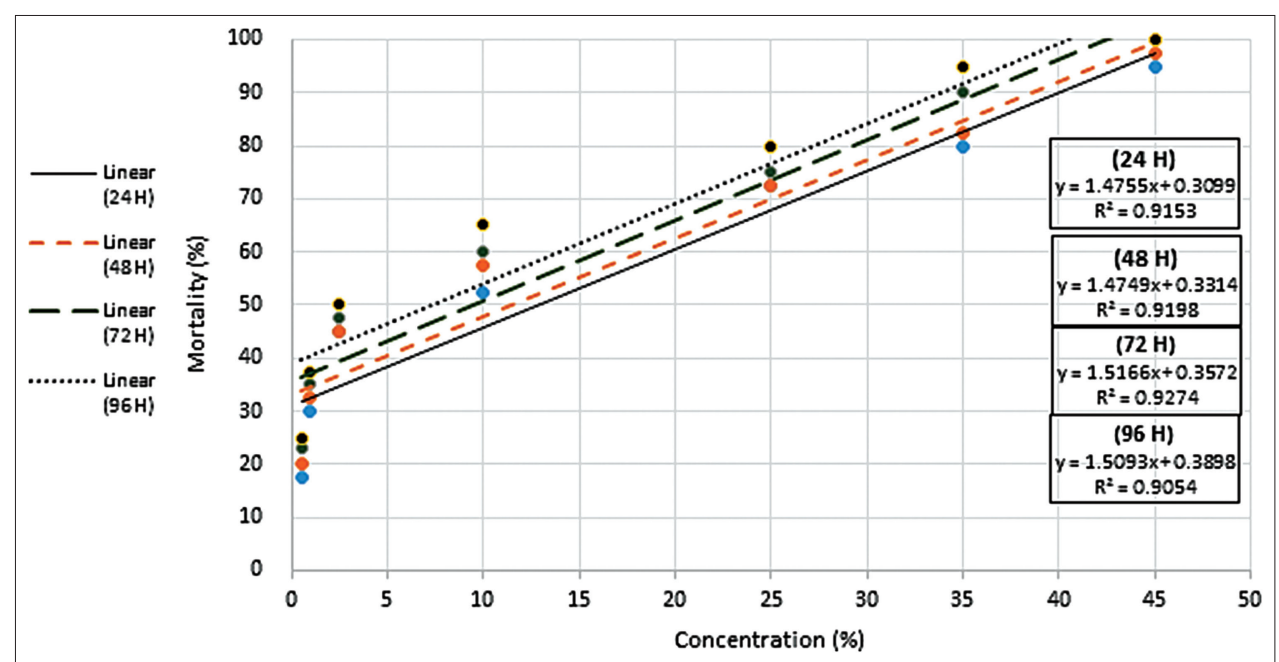

Figure-3: Regression line of imidacloprid against nymphs of German cockroach strains using bait methods within 24-96 h.

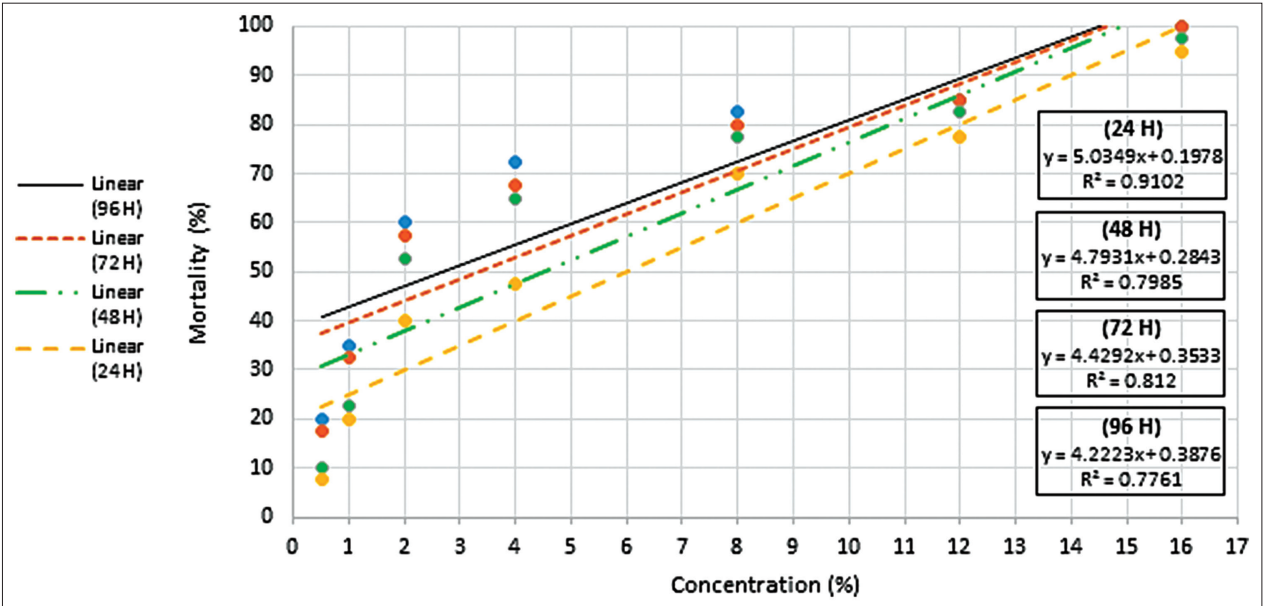

Figure-4: Regression line of chlorpyrifos against nymphs of German cockroach strains using bait methods within 24-96 h.

Although the concentration of this insecticide in the present study was between $0.5 \%$ and $45 \%$, the gel formulation was usually used in the form of $15.2 \%$ concentration. Such a concentration of imidacloprid is lethal for all German cockroach stages. The best conditions for using this formulation are in temperatures below $15^{\circ} \mathrm{C}$ and free from other types of foods [22].

\section{Conclusion}

According to the results, the highest mortality rate was observed in the ingestion of imidacloprid bait within the first $48 \mathrm{~h}$ after exposure to the insecticide. This point can be very important in controlling pests because most cockroaches die during this period. On the other hand, although the results of this study are limited to German cockroach insectarium strain, it can be demonstrated that the toxic effect of this poison is favorable, and therefore, its evaluation in the field studies can be considered as essential and practical.

\section{Authors' Contributions}

$\mathrm{MB}$ and $\mathrm{MK}$ designed the study. AAR, AS, $\mathrm{HRB}, \mathrm{MK}$, and JN gathered the data. MB, MK, and AS interpreted the results and analyzed the data. MB,
MK, and AS prepared the manuscript. All authors read and approved the final manuscript.

\section{Acknowledgment}

The authors are grateful to the Research Deputy of Tehran University of Medical Science, Tehran, Iran. This project was financially supported by Tehran University of Medical Sciences, Iran under the project number: IR.TUMS.VCR.REC.1397.083.

\section{Competing Interest}

The authors declare that they have no competing interests.

\section{Publisher's Note}

Veterinary World (Publisher of International Journal of One Health) remains neutral with regard to jurisdictional claims in published institutional affiliation.

\section{References}

1. van den Berg $\mathrm{H}$, Zaim $\mathrm{M}$, Yadav RS, Soares A, Ameneshewa B, Mnzava A, et al. Global trends in the use of insecticides to control vector-borne diseases. Environ Health Perspect 2012;120:577-82.

2. Shahraki GH, Parhizkar S, Nejad AR. Cockroach infestation and factors affecting the estimation of cockroach population 
in urban communities. Int J Zool 2013;2013:1-6.

3. Solomon F, Belayneh F, Kibru G, Ali S. Vector potential of Blattella germanica (L.) (Dictyoptera: Blattidae) for medically important bacteria at food handling establishments in Jimma town, Southwest Ethiopia. Biomed Res Int 2016;2016:1-6.

4. Nasirian, H. Rapid elimination of German cockroach, Blattella germanica, by fipronil and imidacloprid gel baits. J Arthropod Borne Dis 2008;2:37-43.

5. Dingha BN, O’Neal J, Appel AG, Jackai LE. Integrated pest management of the German cockroach (Blattodea: Blattellidae) in manufactured homes in rural North Carolina. Fla Entomol 2016;99:587-92.

6. Ladonni H. Evaluation of three methods for detecting permethrin resistance in adult and nymphal Blattella germanica (Dictyoptera: Blattellidae). J Econ Entomol 2001;94:694-7.

7. Zahraei-Ramazani AR, Saghafipour A, Vatandoost H. Control of American cockroach (Periplaneta americana) in municipal sewage disposal system, central Iran. J Arthropod Borne Dis 2018;12:172-9.

8. Salehi A, Vatandoost H, Hazratian T, Sanei-Dehkordi A, Hooshyar H, Arbabi M, et al. Detection of bendiocarb and carbaryl resistance mechanisms among German cockroach Blattella germanica (Blattaria: Blattellidae) collected from Tabriz hospitals, East Azerbaijan province, Iran in 2013. J Arthropod Borne Dis 2016;10:403-12.

9. Ko AE, Bieman DN, Schal C, Silverman J. Insecticide resistance and diminished secondary kill performance of bait formulations against German cockroaches (Dictyoptera: Blattellidae). Pest Manag Sci 2016;72:1778-84.

10. Zhu F, Lavine L, O’Neal S, Lavine M, Foss C, Walsh D. Insecticide resistance and management strategies in urban ecosystems. Insects 2016;7:E2.

11. Simon-Delso N, Amaral-Rogers V, Belzunces LP, Bonmatin JM, Chagnon M, Downs C, et al. Systemic insecticides (neonicotinoids and fipronil): Trends, uses, mode of action and metabolites. Environ Sci Pollut Res Int 2015;22:5-34.

12. Eaton DL, Daroff RB, Autrup H, Bridges J, Buffler P,
Costa LG, et al. Review of the toxicology of chlorpyrifos with an emphasis on human exposure and neurodevelopment. Crit Rev Toxicol 2008;38 Suppl 2:1-25.

13. World Health Organization. Tentative Instructions for Determining the Susceptibility or Resistance of Cockroaches to Insecticides. Technical Report Series No. 443. Geneva: World Health Organization; 1970.

14. Díaz C, Bisset JA, González T, Rodríguez MM. Resistance to organophosphate, carbamate, and pyrethroid insecticides in Blattella germanica (Dictyoptera: Blattellidae) in 2 municipalities of the city of Havana. Rev Cubana Med Trop 1994;46:130-2.

15. Agrawal VK, Tilak R. Field performance of imidacloprid gel bait against German cockroaches (Dictyoptera: Blatellidae). Indian J Med Res 2006;124:89-94.

16. Tomizawa M, Casida JE. Neonicotinoid insecticide toxicology: Mechanisms of selective action. Annu Rev Pharmacol Toxicol 2005;45:247-68.

17. Kaakeh W, Reid BL, Bohnert TJ, Bennett GW. Toxicity of imidacloprid in the German cockroach (Dictyoptera: Blattellidae), and the synergism between imidacloprid and Metarhizium anisopliae (Imperfect fungi: Hyphomycetes). J Econ Entomol 1997;90:473-82.

18. Wen Z, Scott JG. Cross-resistance to imidacloprid in strains of German cockroach (Blattella germanica) and house fly (Musca domestica). Pestic Sci 1997;49:367-71.

19. Rust MK, Reierson DA. Chlorpyrifos resistance in German cockroaches (Dictyoptera: Blatellidae) from restaurants. J Econ Entomol 1991;84:736-40.

20. Siegfried BD, Scott JG, Roush RT, Zeichner BC. Biochemistry and genetics of chlorpyrifos resistance in the German cockroach, Blattella germanica (L). Pestic Biochem Physiol 1990;38:10-21.

21. Dong K, Scott JG. Synergism of chlorpyrifos against the German cockroach, Blattella germanica. Med Vet Entomol 1992;6:241-3.

22. Appel AG, Tanley MJ. Laboratory and field performance of an imidacloprid gel bait against German cockroaches (Dictyoptera: Blattellidae). J Econ Entomol 2000;93:112-8. 